\title{
INFLUENCE OF MOISTURE CONTENT ON AERODYNAMIC PROPERTIES OF AGRICULTURAL PRODUCTS IN SEPARATION OF IMPURITIES PROCESS
}

\author{
Gheorghe Stroescu, Anisoara Paun, Iulian Voicea, Catalin Persu, Andreea Matache, George Bunduchi \\ National Institute of Research-Development for Machines and Installations \\ Designed to Agriculture and Food Industry, Romania \\ gigistroescu62@gmail.com, ani_paun@yahoo.com,voicea_iulian@yahoo.com, \\ persucatalin@yahoo.com, andmatache@yahoo.com, georgebund@yahoo.com
}

\begin{abstract}
Knowing the particularities of the vegetable plants' seeds is of particular practical importance, because on their basis the conditioning technologies are realized and the cultivation technologies are managed both in the field and in the protected spaces. Seed quality is a relative notion due to the fact that the seeds of some species may have different destinations: food or feed consumption, sowing or industrialization. The production and quality of any agricultural crop is determined both by the factors that act from the time of sowing to the harvesting, as well as by those that directly influence the seeds before sowing. Quality seeds are the basic block of the vegetable production system. Proper processing after seed harvesting is important to maximize the yield, longevity, vigour and overall quality. Based on these considerations, the theoretical and experimental information on the influence of some factors on the aerodynamic properties of vegetable seeds will be presented. In order to highlight these influences, experiments with various seeds will be carried out on a seed conditioning module for vegetable species-MCSL made at our institute. The quality of seed separation in this module depends on the uniformity degree of the field of air velocities in the working area, the stability of this field and its extent. The seed conditioning module for vegetable species is designed to improve the technologies for organic seed production in the case of vegetable, flower, industrial plant, cereal seeds; for solving practical problems regarding the production of seeds in vegetable crops.
\end{abstract}

Keywords: seed, conditioning, aerodynamic properties.

\section{Introduction}

The seed is the biological factor of the production that contributes to obtaining a qualitative and sufficient production. Seed quality is a relative notion due to the fact that the seeds of some species may have different destinations: food or feed consumption, sowing or industrialization (N. Bucurescu et al., 1992). One of the most important aspects of seed quality is represented by seed qualities, namely, all the features that reflect the usefulness of the seeds for sowing. These depend directly on the purity of the seed material, the lack of impurities and damaged seeds depending on the basic species.

A considerable increase in vegetable growing productivity can be achieved only through increased efforts to mechanize and automate the production processes, to provide a high quality seed material and to reduce the consumption of manual labour [1-3].

Although only high quality seed is used for sowing, it is necessary that it is subjected to preparatory work prior to sowing, which aims to increase the agrobiological value of the seeds, to prevent the transmission of diseases, pests and to ensure faster germination. For this reason, knowing the particularities of the vegetable plants' seeds is of particular practical importance, because on their basis the conditioning technologies are realized and the cultivation technologies in the field, as well as in the protected spaces. Seed sorting and calibration is done with the purpose of separating the healthy, whole, viable seeds, with higher quality properties, from other impurities [4].

In the vegetable plant culture it was experimentally found that size sorting (calibration) and the use of large-scale fractions for sowing ensure efficient production increases, as well as better product early maturity and quality. The research carried out by Hosslin, Mappes and Steib showed that when, in the case of radish, small seed was used, the commercial production on the plot was $44.8 \mathrm{~kg}$, when large seed was used, the production was $52.4 \mathrm{~kg}$, so an increase of $16.9 \%$ was registered. In the case of kohlrabi, when small seed was used, the production was $56.3 \mathrm{~kg}$, and when big seed was used, it was $64.8 \mathrm{~kg}$, ensuring a $15 \%$ increase $[5 ; 6]$.

\section{Materials and methods}

Since production quality depends on seed quality, it must be given special attention. Considering the importance of the conditioning process of vegetable crops' seeds, in order to obtain the highest 
quality seed material INMA developed a seed conditioning module for vegetable species-MCSL, Figure 1, that responds to the demands of the vegetable and flower seed producers. This module can also be used to separate impurities from cereal seeds [7].

a)

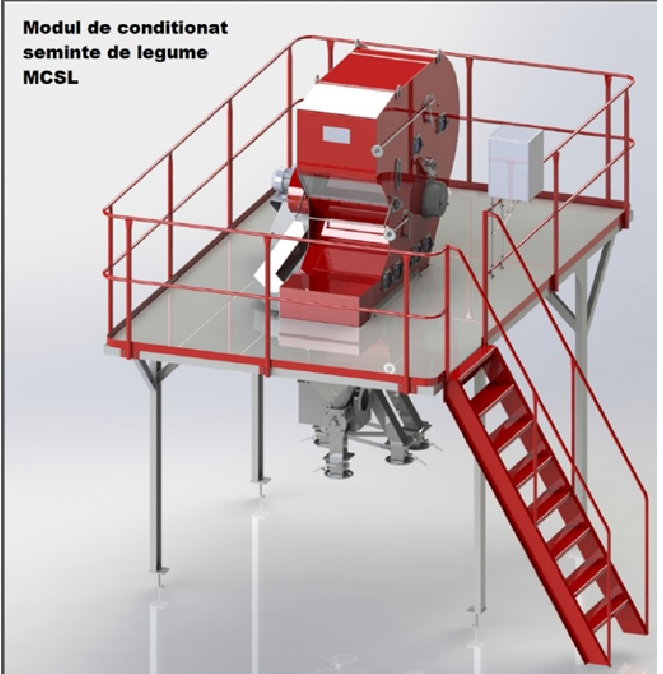

b)

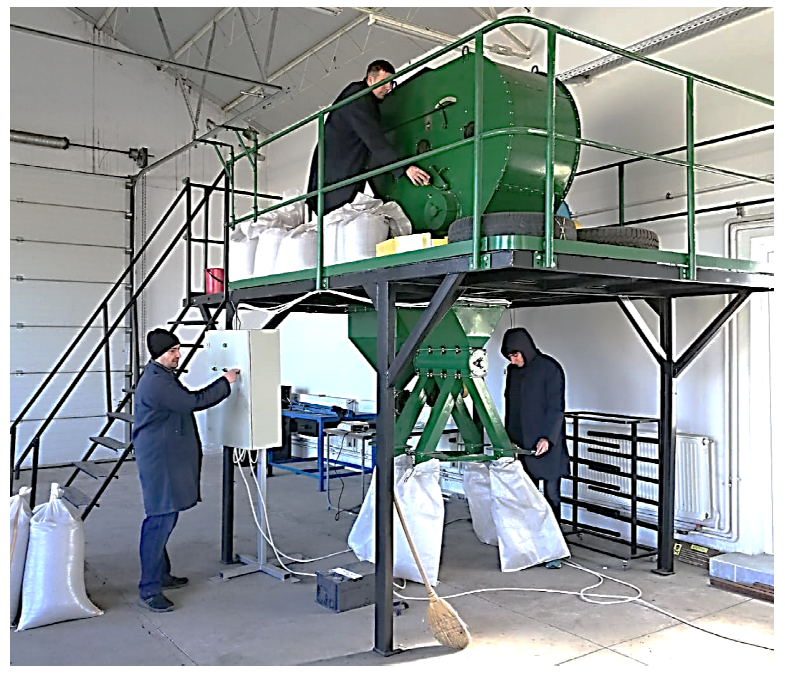

Fig. 1. Seed conditioning module for vegetable species: $a$ - MCSL 3 D; $b$ - MCSL operating

The seed conditioning module for vegetable species MCSL achieves the separation of light impurities into two fractions from the seed mass and their sorting (having the same size, but different shape, mass and roughness) into three fractions.

The area affected by the airflow within the seed conditioning module MCSL is an ascending air sorting column created by a fan.

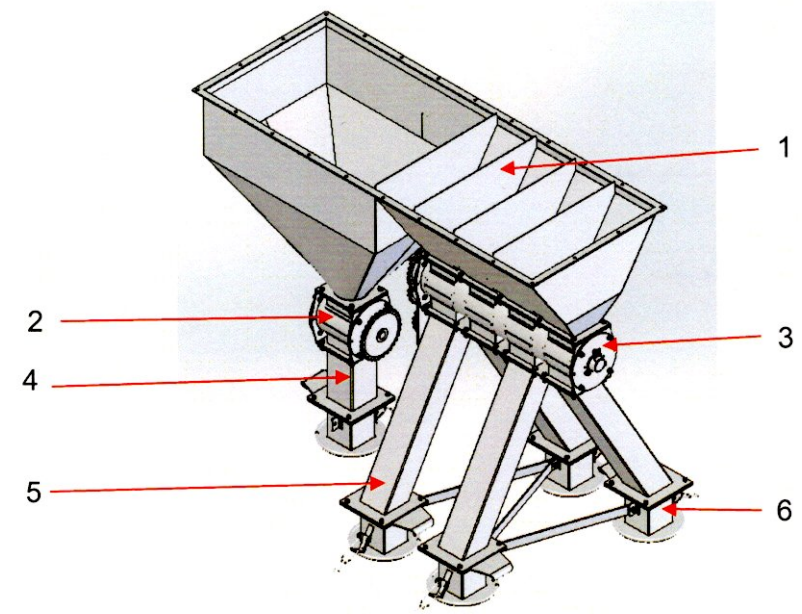

Fig. 2. Sorting system MCSL 2.0: 1 - collection body; 2 - lock MCSL;

3 - lock with 4-way; 4 - vertical tube; 5 - tilt tube; 6 - bag mouth

The MCSL aerodynamic sorter is a metallic construction divided inside into several channels, which ensure the displacement of the seed mass with impurities in order to be separated by fractions.

The MCSL 2.0 sorting system, Figure 2, is connected to the bottom of the aerodynamic sorter. It consists of four transfer funnels of the first four fractions to a four-way lock and a funnel (below the second filing room) linked to a simple lock.

The locks are operated by a gear motor with two chain transmissions. Under the locks five exhaust pipes are attached, each being provided with a damper plate and a sack mouth.

The seed conditioning module for MCSL vegetable species has been designed and manufactured so that the separation of foreign bodies from the mass of vegetable seeds will achieve their aerodynamic properties. 
The essential parameter that characterizes the seed separation process with the help of air flow is the floating speed [8].

For the removal of foreign bodies from the mass of the product it is necessary that the velocity of the air currents should hold in suspension and transport the particles to be removed from the mass of the product. The velocity of the air in which the particles circulate is called the drive speed. This must be greater than the float.

During the separation, a particle of mass $m_{p}$, immersed in the fluid flowing with velocity, $v_{f}$, density $\rho_{f}$ and the projection surface of the particle, $S_{p}$ in the direction of the travel speed, is subjected to a resistance force $F_{r}$ :

$$
F_{r}=c_{r} S_{p} \frac{\rho_{f} v_{f}^{2}}{2},
$$

where $F_{r}$ - resistance force, $\mathrm{N}$;

$c_{r}$ - resistance coefficient (coefficient indicating resistance encountered by a body moving in a fluid), dimensionless;

$S_{p}$ - projection surface of the particle in the direction perpendicular to the direction of the air flow, $\mathrm{m}^{2}$;

$\rho_{f}$ - fluid density, $\mathrm{kg} \cdot \mathrm{m}^{-3}$;

$v_{\mathrm{f}}$ - fluid or gas velocity, $\mathrm{m} \cdot \mathrm{s}^{-1}$

A particle of mass $m_{p}$ in free fall obtains a limit velocity or critical velocity, at which the net gravitational force $G$ equals the upward aerodynamic resistance force $F_{r}$. When the seed velocity is reached under equilibrium conditions, the particle motion will be upward or downward depending on the particle density, $\rho_{p}$ lower or higher than that specific to fluids. Therefore, knowing the particle floating velocity defines the range of air velocities that influence the effective separation of impurities from the mass of seeds in the air stream $[9 ; 10]$.

The coefficient of resistance can be obtained in terms of the floating speed (when the fluid velocity is equal to the floating velocity of the particle) as:

$$
\begin{aligned}
& v_{f}=v_{p}, \\
& G=F_{r},
\end{aligned}
$$

where

$$
\begin{gathered}
g=m_{p} g\left[\frac{\rho_{p}-\rho_{f}}{\rho_{p}}\right] . \\
m_{p} g\left[\frac{\rho_{p}-\rho_{f}}{\rho_{p}}\right]=c_{r} S_{p} \frac{\rho_{f} v_{f}^{2}}{2} .
\end{gathered}
$$

In relation 4 we note with $w=m_{p} g$ the mass of the particle and the relation for $v_{p}$ will be:

$$
\begin{gathered}
v_{p}=\left[\frac{2 w\left(\rho_{p}-\rho_{f}\right)}{\rho_{p} \rho_{f} c_{r} S_{p}}\right] \frac{1}{2}, \\
c_{r}=\frac{2 w\left(\rho_{p}-\rho_{f}\right)}{S_{p} \rho_{p} \rho_{f} v_{f}^{2}},
\end{gathered}
$$

where $\rho_{p}$ - particle density, $\mathrm{kg} \cdot \mathrm{m}^{-3}$;

$m_{p}$ - particle mass, $\mathrm{kg}$;

$v_{\mathrm{p}}$ - particle floating velocity, $\mathrm{m} \cdot \mathrm{s}^{-1}$;

$g$ - gravitational acceleration, $\mathrm{m} \cdot \mathrm{s}^{-2}$

In general, the coefficients that are taken into account are determined experimentally.

For the spherical bodies with the equivalent spherical diameter of the particles, $d_{p}$ the projection surface of the particle, $S_{p}$ can be determined by the relation: 


$$
S_{p}=\frac{\pi d_{p}^{2}}{4} .
$$

The equivalent dimension means the side of the cube or the diameter of the sphere, which volume is equal to that of the particle. Most agricultural products have irregular shapes, and for this reason, in calculations they are considered as equivalent spherical diameter $\varnothing$.

$$
\varnothing=\left[\frac{(a b c)^{\frac{1}{3}}}{a}\right]
$$

where $a, b, c$ - seed length, width, thickness, $\mathrm{mm}$

$$
d_{p}=\left[a \frac{(b+c)^{2}}{4}\right]^{\frac{1}{3}} .
$$

For spherical seeds (particles), for example, peas, at which

$$
G=\gamma_{p} \cdot \frac{\pi \cdot d p^{3}}{6}
$$

and the floating velocity has the expression:

$$
v_{p}=\sqrt{\frac{2}{3} d p \frac{\gamma_{p}}{\gamma_{a}} \frac{g}{c_{r}}}
$$

or

$$
v_{p}=\sqrt{\frac{2}{3} d p \frac{\gamma_{p}}{\rho_{a} c_{r}}},
$$

where $\gamma_{p}$-specific (volumetric) weight of the seeds;

$d_{p}$ - diameter of seeds (particles), $\mathrm{mm}$;

$\rho_{a}-$ air density, $\mathrm{kg} \cdot \mathrm{m}^{-3}$.

The theory of aerodynamic characteristics of regular shaped bodies is well developed; however, the seeds, especially those of vegetables, industrial plants, flowers are non-compliant $[11 ; 12]$.

\section{Results and discussions}

In order to verify the functional parameters of the seed conditioning module MCSL and to analyse the aerodynamic properties of the vegetable seeds, experiments were performed under operating conditions. The experiments were carried out with pea and bean seeds for different types of moisture and the results obtained are presented in Table 1 and with the aerodynamic properties of the seeds, established in the testing laboratory.

Physical-mechanical properties of the seeds being tested

\begin{tabular}{|c|c|c|c|c|}
\hline Seed name & $\begin{array}{c}\text { Floating velocity } \\
\mathbf{m} \cdot \mathbf{s}^{-1}\end{array}$ & $\begin{array}{c}\text { Resistance } \\
\text { coefficient } \boldsymbol{c}_{\boldsymbol{r}}\end{array}$ & $\begin{array}{c}\text { Bearing } \\
\text { coefficient }\end{array}$ & $\begin{array}{c}\text { Specific weight } \\
\mathbf{k g} \cdot \mathbf{m}^{-\mathbf{3}}\end{array}$ \\
\hline Pea & $15.50-17.50$ & $0.190-0.229$ & $0.031-0.141$ & 1264 \\
\hline Bean & $12.48-14.03$ & $0.159-0.259$ & $0.049-0.063$ & 1220 \\
\hline
\end{tabular}

For this testing several dozen attempts were made to determine as accurately as possible and a sufficient amount of material was used so as to avoid that any errors influence the significance of the testing. Each test was repeated at least 3 times and an arithmetic mean of the results was made. Table 2 presents the results obtained in the experiments.

The different variations of the floating speed were transposed in graphic form depending on the floating velocity, on the density of the particle and the resistance coeficent for pea and bean. 
Aerodynamic properties of seeds at different types of moisture

Table 2

\begin{tabular}{|c|c|c|c|c|c|}
\hline $\begin{array}{c}\text { Seed } \\
\text { moisture, } \%\end{array}$ & $\begin{array}{c}\text { Dimensions } \\
\boldsymbol{d}_{\boldsymbol{p}}, \mathbf{m m}\end{array}$ & $\begin{array}{c}\text { Density, } \\
\mathbf{~ k g} \cdot \mathbf{m}^{-\mathbf{3}}\end{array}$ & Sphericity $\varnothing$ & $\begin{array}{c}\text { Floating } \\
\text { velocity, m. } \mathbf{s}^{-\mathbf{1}}\end{array}$ & $\begin{array}{c}\text { Resistance } \\
\text { coefficient, } \boldsymbol{c}_{\boldsymbol{r}}\end{array}$ \\
\hline \multicolumn{7}{|c|}{ Pea } \\
\hline 9.49 & $5.79 \pm 0.34$ & 1583.90 & $0.830 \pm 0.02$ & 7.52 & 0.66 \\
\hline 11.08 & $6.33 \pm 0.32$ & 1473.20 & $0.830 \pm 0.03$ & 9.95 & 0.61 \\
\hline 12.50 & $6.51 \pm 0,35$ & 1388.70 & $0.830 \pm 0.03$ & 11.3 & 0.59 \\
\hline 15.98 & $6.81 \pm 0.41$ & 1259.31 & $0.830 \pm 0.02$ & 10.1 & 0.54 \\
\hline \multicolumn{7}{|c|}{ Bean } \\
\hline 9.49 & $7.87 \pm 0.41$ & 1250.25 & $0.623 \pm 0.04$ & 6.7 & 0.150 \\
\hline 11.08 & $8.79 \pm 0.33$ & 1220.25 & $0.623 \pm 0.02$ & 10.2 & 0.131 \\
\hline 12.50 & $9.10 \pm 0.41$ & 1210.30 & $0.623 \pm 0.02$ & 13.6 & 0.124 \\
\hline 15.98 & $9.42 \pm 0.29$ & 1206.23 & $0.623 \pm 0.03$ & 16.5 & 0.115 \\
\hline
\end{tabular}

These preliminary tests were carried out with previously predefined values depending on the characteristics of the equipment, the values obtained are useful for an overview of the interdependence of the factors that determine the moisture content.

The interdependence of the factors involved in the influence of moisture content and their understanding can lead to better separation of impurities with this type of equipment and its adjustment at an optimal level.

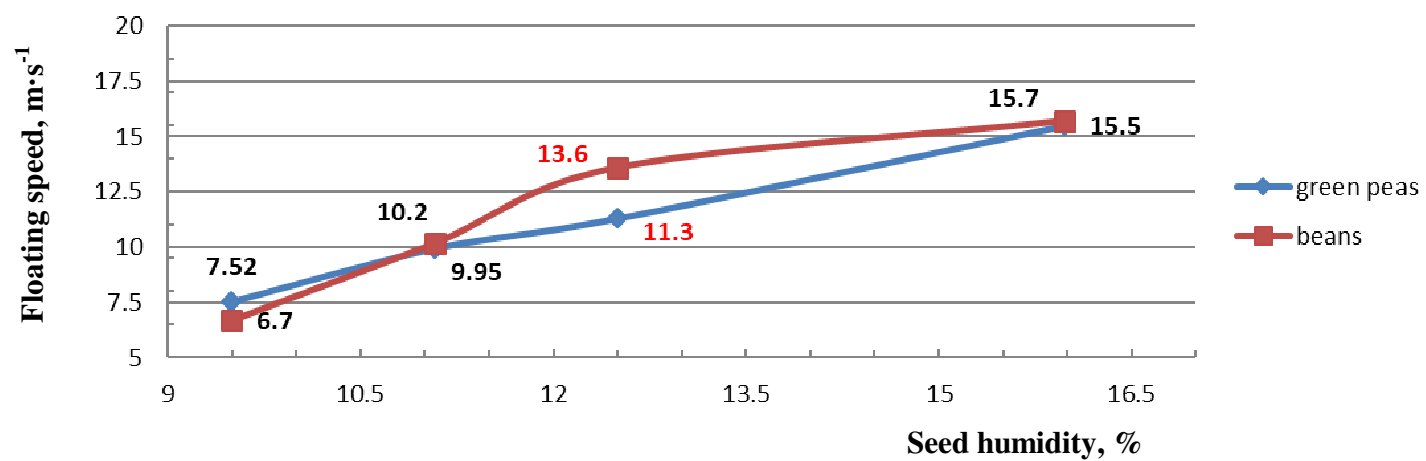

Fig. 3. Influence of moisture on the floating velocity

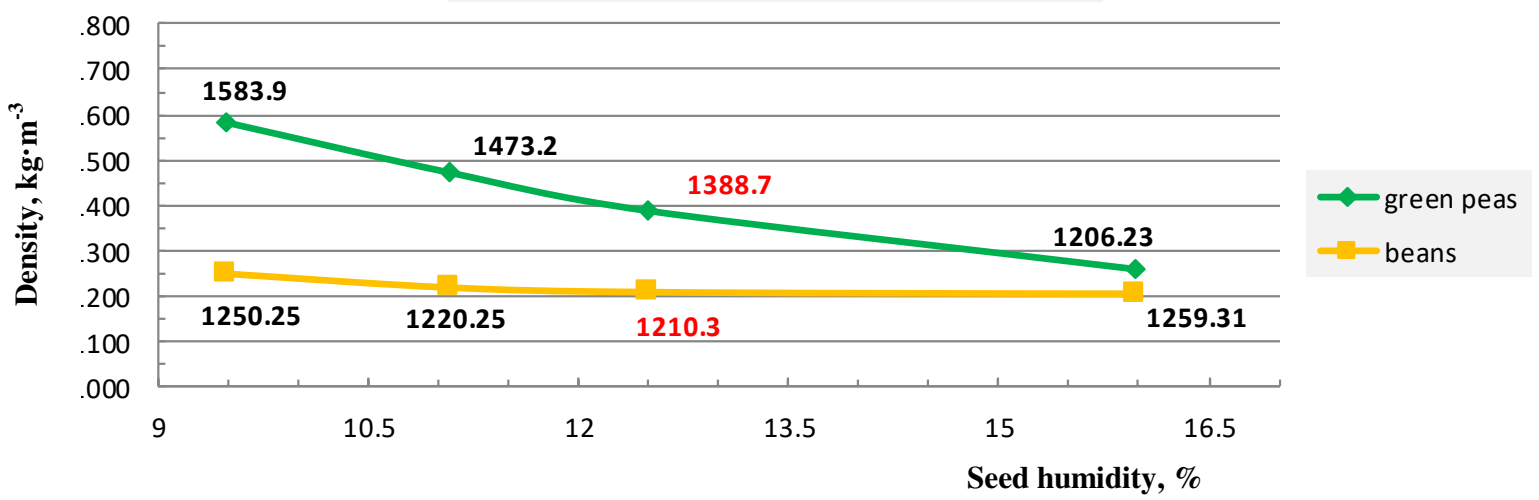

Fig. 4. Influence of moisture on the density of the particle

According to Figure 4 and the above determinations, the density sphericity of the bean seeds remains constant after the increase of the moisture degree.

Effect of the moisture content on geometric properties: volume and $S_{p}$ - the projection surface of the particle in the direction perpendicular to the direction of the air flow (implicitly the dimensions of the seeds) in the first phase increase and tend to remain constant. 


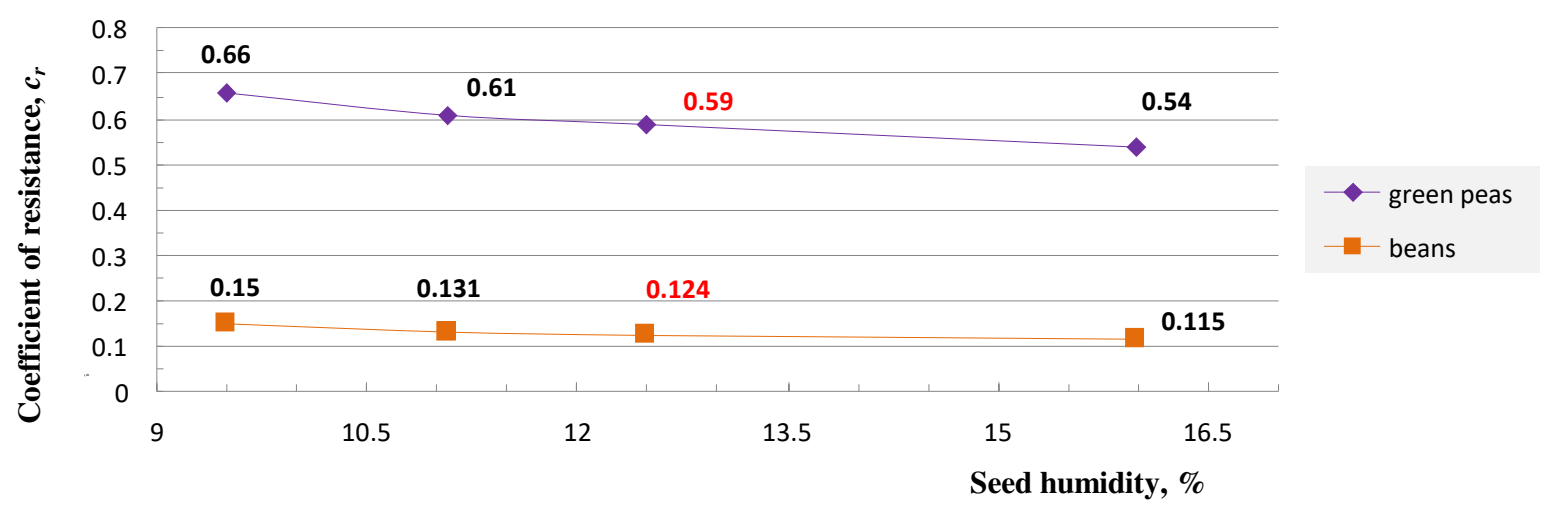

Fig. 5. Influence of moisture on the resistance coefficient $c_{r}$

Effect of the moisture content on gravimetric properties: it was found that the gravimetric properties of all selected seeds are inversely proportional to their moisture content.

Effect of the moisture content on friction properties: all friction properties increased with the increase in the moisture content.

\section{Conclusions}

Seed quality is critical for agricultural production: poor seed limits the potential yield and reduces the productivity of the farmer's work. There are four basic parameters for seed quality attributes:

- physical qualities of the seeds in the special seed lot;

- physiological qualities, which refer to aspects of seed performance;

- genetic quality, which refers to the specific genetic characteristics of different seeds;

- seed health, which refers to the presence or absence of diseases and pests within a seed lot.

The experiments were performed in inclined air flow.

\section{Acknowledgements}

This paper was financed with the support of the National Agency for Scientific Research and Innovation, Programme FARMING TOMORROW - ENSURING ENVIRONMENT SUSTAINABILITY BY INCREASING COMPETITIVENESS OF IMPROVEMENT FOR ECOLOGICAL AGRICULTURE (UEFISCDI PN-III-P1-1.2-PCCDI-2017-0850, Contract: 14PCCDI/06.03.2018), project component 4 "Making efficient the technology of producing ecological seeds for legume species by achieving a module of seed conditioning".

This paper was financed by grant of the Romanian Education and Research Ministry, through Programme 1 - Development of the national research-development system, sub-programme 1.2 Institutional performance - Projects for financing excellence in RDI, contract no. 16PFE

\section{References}

[1] Bucurescu N., Roman D. Seed and its preparation for sowing, Ceres Publishing House, Bucharest, 1992.

[2] Barsky E., Barsky M. Relationship between fractional separation curves and quantitative optimization criteria in the separation of pourable materials, Physical Separation in Science and Engineering, 2004, vol. 13, pp. 41-51.

[3] Căsăndroiu T. Primary processing and agricultural products storing, lithographed course, University Politehnica of Bucharest, 1993.

[4] Ciobanu V.G., A.L. Visan, Paun A, Nedelcu A. Comparative study regarding seed sorting equipment and the importance of implementing smart systems within the working process, JoKULL Journal 2015, Vol.64, No.9, ISSN 0449-0576, pp.91-100.

[5] Ciofu R. et al. Dissertation on vegetable growing, CERES, Publishing House, Bucharest, 2004.

[6] Danciu I. Cereals cleaning, Publishing House of "Lucian Blaga" University, Sibiu, 2001. 
[7] Păun A., Stroescu Gh., Bogdanof G., Vlăduţ N-V - Module for pre-cleaning vegetable seeds, patent application no. A-00986/28.11.2018.

[8] Zewdu A.D. Aerodynamic properties of the grain and straw material, Biosystems Engineering Journal, 2007, vol. 98, pp. 304-309.

[9] Barsky E., Barsky M. Relationship between fractional separation curves and quantitative optimization criteria in the separation of pourable materials, Physical Separation in Science and Engineering, 2004, vol. 13, pp. 41-51.

[10] Didyh V.F. Improving the efficiency of drying agricultural plant materials: monograph, 2002, Lutsk pp.165.

[11]Rus Fl. Separation operations in the food industry, Publishing House Transilvania University of Brasov, ISBN-973-8124-31-X, 2001, pp. 75-101.

[12] Stroescu Gh., Păun A. \&co. Technology for obtaining environmentally-friendly seeds and sowing material for vegetable species, Proceedings of international Symposium ISB-INMATEHAgricultural and Mechanical Engineering, 1-3 Nov. 2018, ISSN 2537-3773, pp. 467-472; 